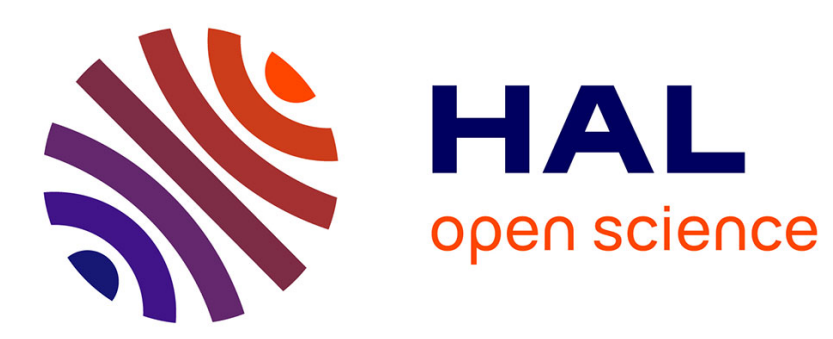

\title{
Study of an Industrial FEM tool for line boring process of cylinder blocks
}

Shadan Tabibian, Philippe Lorong

\section{To cite this version:}

Shadan Tabibian, Philippe Lorong. Study of an Industrial FEM tool for line boring process of cylinder blocks. ESAFORM 2015, Apr 2015, Graz, Austria. pp.1171-1182, 10.4028/www.scientific.net/KEM.651-653.1171 . hal-01202975

\section{HAL Id: hal-01202975 \\ https://hal.science/hal-01202975}

Submitted on 22 Sep 2015

HAL is a multi-disciplinary open access archive for the deposit and dissemination of scientific research documents, whether they are published or not. The documents may come from teaching and research institutions in France or abroad, or from public or private research centers.
L'archive ouverte pluridisciplinaire HAL, est destinée au dépôt et à la diffusion de documents scientifiques de niveau recherche, publiés ou non, émanant des établissements d'enseignement et de recherche français ou étrangers, des laboratoires publics ou privés. 


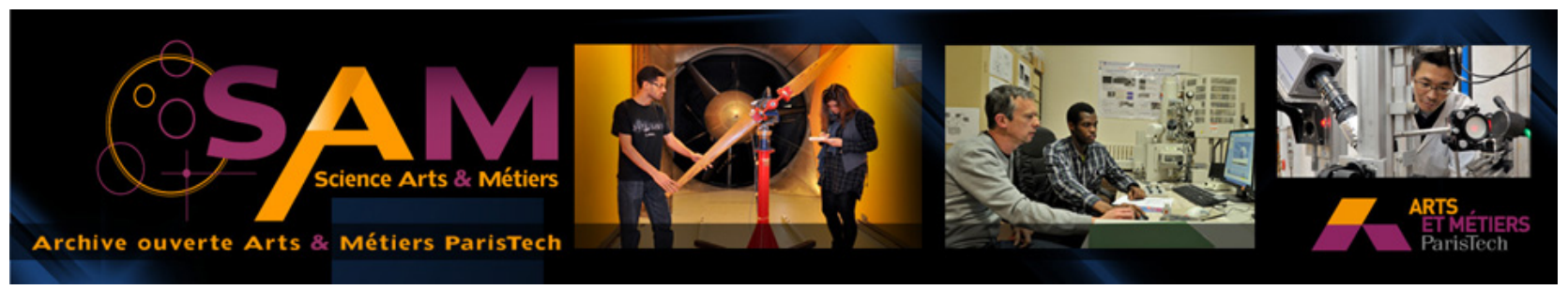

Science Arts \& Métiers (SAM)

is an open access repository that collects the work of Arts et Métiers ParisTech researchers and makes it freely available over the web where possible.

This is an author-deposited version published in: http://sam.ensam.eu

Handle ID: .http://hdl.handle.net/10985/10093

\section{To cite this version :}

Shadan TABIBIAN, Philippe LORONG - Study of an Industrial FEM tool for line boring process of cylinder blocks - In: ESAFORM 2015, Autriche, 2015-04-15 - Key Engineering Materials - 2015 


\title{
Study of an Industrial FEM tool for line boring process of cylinder blocks
}

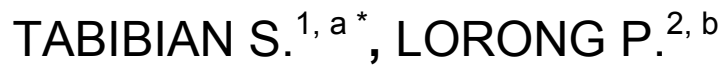 \\ ${ }^{1}$ Renault SAS- Centre Technique Guyancourt- 1, avenue du Golf, 78288 Guyancourt, France \\ 2 Ecole Nationale Supérieure d'Arts et Métiers- 151, Boulevard de l'Hôpital, 75013 Paris, France \\ a shadan.tabibian@renault.com, b philippe.lorong@ensam.eu
}

Keywords: Machining process, line boring, automotive industry, cylinder block, force cutting law, form defect, FEM modeling.

\begin{abstract}
The aim of this study is to realize a simple simulation tool, in order to predict the form defect of cylinder block bore liners in the moment of rough boring process. In this study a simple static FEM model, based on the cylinder block geometry, is proposed to predict the form defect of the bore liners in the moment of process.

The simulation results put forward that the clamping condition plays an import role in the bore distortion. Consequently, optimizing the clamping pressure and its localization is critical, before cutting parameters adjustment, in line boring process. Experimental validation is performed in parallel with the simulation. The first correlation between experimentation and simulation results shows that the first influent factor which disturbs the correlation is the initial form defect of rough part due to the casting process. Integration of casting form defect in the simulation is crucial and should be taken into account in the next studies.
\end{abstract}

\section{Introduction}

Geometrical defect predictions is critical for Process Engineering in order to optimize all machining sequences in the production line, to garantee the final product, according to the norms defined by the Design Engineering. In revenge, Process Engineering can suggest a new product design according to geometrical defect predictions. Simulation can significantly reduce the time of ProcessProduct parameters adjustment (pre-project) [1].

Although not as much as milling and turning, little research effort has been reported in predicting the boring process [2, 3]. Milling and turning issues are already well covered by available commercial codes such as CAD/CAM, Catia or Pro-Engineer (NC programming, tool collisions, time cycles ...) or specialized software such as CutPro for chatter prediction [4]. However, substantial advancements are to be made to meet all the industrial needs in manufacturing process simulation [5].

For industrial parts, a numerical method such as the finite element method is required to obtain the part deformations occurring along the tool path. A few methods are proposed in the literatures that are mostly based on a time approach, which implies a complex interpolation scheme to obtain the defect of the whole machined surface [5]. 


\section{Force cutting law modeling}

Definition of force cutting law modeling. Cutting Force is a force that is generated by the cutting tool as it machines the workpiece. It can be divided into primary and secondary cutting forces. Primary cutting force is a cutting force that is directly generated by the relative motion of the cutting tool with respect to the work piece during machining. It occurs in the same direction as cutting tool movement. Secondary cutting force is a cutting force that is generated in response to primary cutting forces, for example, vibrations during the machining. Cutting forces modeling is the mathematical representation of a machining process in order to study the effects of varying process parameters on the cutting forces $[6,7]$.

Machining is a process of chip formation. Although the final purpose is to obtain a determined form and shape from the cutting of the material, this has to be done by creating defined chips. Thus, machining is a process in which the components of the process are in such form that the external forces applied can cause the chips to be fractured to several parts. This fracture can be caused by the combination of bending stresses: tensile stress and shear stress. Cutting is a process of extensive stresses and plastic deformations. The high compressive and frictional contact stresses on the tool face result in a substantial cutting force. Knowledge of the cutting forces is essential to make a proper design of the cutting tools, of the fixtures used to hold the workpiece (clamping condition) and cutting tool, for the calculation of the machine tool power, and for the selection of the cutting conditions to avoid an excessive distortion of the workpiece. As the power consumed by the machine to take out the process is always a factor to be optimized, cutting force is one of the most important parameters in the machining operation. In spite of their importance, it is one of the least understood operation parameters of a machining operation $[8,9]$.

Mechanism of cutting. In any machining operation, the unit product of the material removal is called chip. The thickness of the chip is always more than the layer of the metal removed. This is due to plastic deformation of the metal during the cutting process. The separation of the chip from the workpiece takes place by shearing. Frictional forces being generated at the cutting edge result in heat and tool wear.

In the actual cutting of the metal, the tool deforms some of the material and then separates it through plastic deformation. This elastic and plastic deformation of the metal takes place as it approaches and exceeds the yield strength of the material as it moves past the tool face. In this deformation, large forces are produced. For the convenience of analysis and resolution of the resulting cutting force, F, is divided into three components (Fig. 1) [8]:

The tangential force, $F_{c}$, the axial force, $F_{f}$, the radial force, $F_{p}$. 

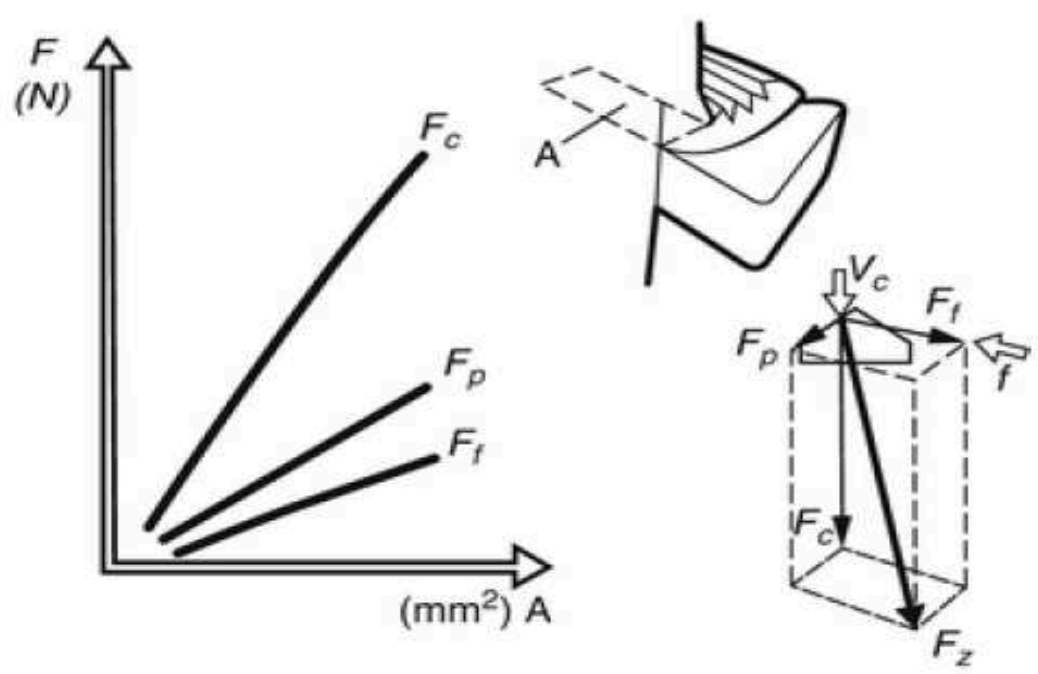

(Fig.1: Cutting force components)

The radial cutting force component $\left(\mathrm{F}_{\mathrm{p}}\right)$ is directed at right angle to the tangential force from the cutting point. The axial cutting force $\left(\mathrm{F}_{\mathrm{f}}\right)$ is directed along the feed of the tool, axially along the direction of machining of the component. This is an important force factor in drilling operations. The cutting ability of the drill geometry will considerably influence the size of the force needed and as a rule the axial feed force requirement rises with the diameter of the drill [1]. The cutting force value is primarily affected by the following cutting conditions:

- Cutting speed, $\mathrm{v}_{\mathrm{c}}$, feed, $\mathrm{f}$, and depth of cut, $\mathrm{a}_{\mathrm{p}}$

- Cutting tool geometry (tool orthogonal rake angle)

- Properties of work material

As it may be expected, the size relationship between the force components varies considerably with the type of machining operation. The tangential force often dominates in milling and turning operations, especially in power requirements. The radial force is of particular interest in boring operations that is the case of our study, and the axial feed force in drilling. The size of the radial cutting force is dependent upon the entering angle used and the nose radius. A $90^{\circ}$ entering angle and small nose radius will minimize the radial cutting force component, which strives to deflect the tool and gives rise to vibrations. Vibration tendency is one consequence of the cutting forces, as well as tool or workpiece deflection [10].

Friction force also comes partly into the process as the material is forced onto the tool at great pressure and high temperature. The pressure depends upon the shear yield strength of the workpiece material and the area of the shear plane.

Force cutting law. Still no satisfactory model exists for calculating cutting forces for all machining processes. However, there are several laws that can be found in the literature that propose different simple and complex models. We study here three of the force cutting law models: linear, Kienzle and affine force cutting law. 
Linear force cutting law. The linear model propose a force cutting law in which cutting force depends to the depth of cut $a_{p}$ (or chip width $b$ ) and feed (f) (or chip height $h$ ) linearly. The expression of each component is as following:

$$
\mathrm{F}_{\mathrm{i}}=\mathrm{K}_{\mathrm{i}} \mathrm{a}_{\mathrm{f}}=\mathrm{K}_{\mathrm{i}} \text { bh with } \mathrm{i}=\mathrm{c}, \mathrm{f}, \mathrm{p}
$$

However, experiments have shown that evolution of different components for the total cutting force is not linear. Thus, this law is only valid for the smaller values of chip height (h). The specific cutting force rate depends to the cutting material and depth of cut $\left(\mathrm{a}_{\mathrm{p}}\right)$. Some specific cutting force values are given in literature [8].

Kienzle force cutting law. Experiments have shown that the cutting force varies proportionally with the cutting width (b) but disproportionally with the cutting height (h). The fundamental Kienzle law associates the value of Specific cutting force with chip height (h) as follow:

$$
\begin{aligned}
& K_{i}=K_{i 1,1}\left(\frac{h}{m m}\right)^{-m_{i}}\left[\mathrm{~N} / \mathrm{mm}^{2}\right] \\
& K_{i}=K_{i 1,1} h^{-m_{i}}
\end{aligned}
$$

Equation 3 is only valid for a specific range of chip height (h). Because in case of an infinite chip height the equation (Eq.3) states that $\mathrm{K}_{\mathrm{i}}$ goes to 0 and there is no need for specific cutting forces that is theoretically incorrect.

Kienzle coefficients $K_{i, 1,1}$ (specific cutting force for the chip area $A_{c}=1 \mathrm{~mm}^{2}$ ) and $m_{i}($ exponent) are determined experimentally. The relations (Eq.4, 5, 6) are used to calculate the cutting forces in the identical condition with the experiment which allowed the determination of Kienzle coefficients values [11]. We can nevertheless apply correction factors if the conditions are not identical.

In order to determine the Kienzle coefficient $\mathrm{K}_{\mathrm{i}, 1,1}$ and $\mathrm{m}_{\mathrm{i}}$ (exponent) values, specific experimental tests should be performed in the laboratory under a specific cutting condition. Some independent cutting parameters such as cutting speed $\left(\mathrm{v}_{\mathrm{c}}\right)$, depth of cut $\left(\mathrm{a}_{\mathrm{p}}\right)$, and feed (f) are selected. Then the measurement of cutting forces (tangential force, $F_{c}$, the axial force, $F_{f}$, the radial force, $F_{p}$ ) was made by three component measuring gauge. Regression analysis needs to be conducted in order to determine Kienzle coefficients $K_{i, 1,1}$ (specific cutting force for the chip area $A_{c}=1 \mathrm{~mm}^{2}$ ) and $m_{i}$ (exponent) [11].

However, it should be noted that $K_{i, 1,1}$ is the specific cutting force for the chip area $A_{c}=1 \mathrm{~mm}^{2}$. Similarly, it should be noted that this expression is only valid over a given range of $\mathrm{h}$ values.

$\left(1-m_{i}\right)$ represents the force increasing rate for a given chip height $(h)$ increasing rate. From equations (Eq.1) and (Eq.3) the expressions of the total cutting force components becomes:

$$
\begin{aligned}
& F_{c}=K_{c 1,1} b h^{1-m_{c}} \\
& F_{f}=K_{f 1,1} b h^{1-m_{f}} \\
& F_{p}=K_{p 1,1} b h^{1-m_{p}}
\end{aligned}
$$

We have to note that in the equations $(E q .4,5,6) \mathrm{K}_{\mathrm{i}, 1,1}$ is the specific cutting force for $\mathrm{A}_{\mathrm{c}}=1 \mathrm{~mm}^{2}$, $K_{f, 1,1}$ is the specific feed force for $A_{c}=1 \mathrm{~mm}^{2}, K_{p, 1,1}$ is the specific passive force for $A_{c}=1 \mathrm{~mm}^{2}, m_{c}$ is the slope coefficient for cutting force, $\mathrm{m}_{\mathrm{f}}$ is the slope coefficient for feed force and $\mathrm{m}_{\mathrm{p}}$ is the slope coefficient for passive force.

Affine force cutting law. Experiments have shown that the variation of the cutting force as a function of chip section thickness gives a fairly correct alignment from a certain value of chip height 
(h). If the chip thickness is in an interval in which the lower limit of the interval is greater than the chip height value (h), we can model the cutting forces by the affine law.

In this interval, we can write the following expression:

$$
F_{i}=b\left(A_{i} h+B_{i}\right) \text { with } \quad \mathrm{i}=\mathrm{c}, \mathrm{f}, \mathrm{p}
$$

There are several ways to determine the coefficients $A_{i}$ and $B_{i}$ :

- The tangent at of a specific point on the Kienzle curve.

- The affine model curve can be determined in a way to get close to the Kienzle model curve in a specific interval range (using the method of least squares, for example). In this way we can identify the coefficients $A_{i}$ and $B_{i}$.

The affine law provides a very good estimation of the cutting forces in a specific interval of chip height (h).

Relation between different components of cutting force. It is possible to describe the cutting force components as functions of the each other. For this it is necessary to know the three following parameters:

- The depth of cut $\mathrm{a}_{\mathrm{p}}$

- Lead angle $\mathrm{K}_{\mathrm{r}}$

- Cutting corner radius or nose radius $r_{\varepsilon}$

Table 1: Relation between different components of cutting force

\begin{tabular}{|c|c|c|c|}
\hline & $\kappa_{r}<60^{\circ}$ & $60^{\circ}<\kappa_{r}<90^{\circ}$ & $90^{\circ}<\kappa_{r}$ \\
\hline$F_{p}$ & $\frac{0,65}{a_{p} /{ }^{0,3}} \times F_{c}$ & $\frac{0,5}{a_{p} / r_{\varepsilon}{ }^{0,4}} \times F_{c}$ & $\frac{0,37}{a_{p} / r_{\varepsilon}{ }^{0,56}} \times F_{c}$ \\
\hline$F_{f}$ & $0,5 \times F_{c}$ & $0,5 \times F_{c}$ & $0,6 \times F_{c}$ \\
\hline
\end{tabular}

So we can deduce a relationship between specific cutting forces as follow:

Table 2: Relation between different specific cutting forces

\begin{tabular}{|c|c|c|c|}
\hline & $\kappa_{r}<60^{\circ}$ & $60^{\circ}<\kappa_{r}<90^{\circ}$ & $90^{\circ}<\kappa_{r}$ \\
\hline$K_{p}$ & $\frac{0,65}{a_{p} /_{\varepsilon}{ }^{0,3}} \times K_{c}$ & $\frac{0,5}{a_{p} / r_{\varepsilon}{ }^{0,4}} \times K_{c}$ & $\frac{0,37}{a_{p} / r_{\varepsilon}{ }^{0,56}} \times K_{c}$ \\
\hline$K_{f}$ & $0,5 \times K_{c}$ & $0,5 \times K_{c}$ & $0,6 \times K_{c}$ \\
\hline
\end{tabular}

Choice of force cutting law. The choice of force cutting law for boring simulation tool was based on the Kienzle law. Indeed, this model has the advantage of better estimation of cutting force evolution because of disproportionate dependence on the chip height $(\mathrm{h})$.

Furthermore, the coefficients of Kienzle model are obtained experimentally and can be adjusted if the process parameters such as cutting conditions or cutting tool parameters, are slightly different 
from the experiment in which the process parameters are define. In rough line boring process the vibration is very low and the chip thickness is relatively high $(4 \mathrm{~mm})$. In such a condition in which the vibration and the chattering are not the important issues, choice of Kienzle law appears appropriate.

\section{Rough line boring FEM tool}

For industrial parts, a numerical method such as the finite element method is required to obtain the part deformations occurring along the tool path. A few methods are proposed in the literature. Most are based on a time domain approach, which implies a complex interpolation scheme to obtain the defect of the whole machined surface [12].

The aim of this study was to provide a user friendly simulation tool for rough line boring of cylinder blocks in static domain. Thus, the tool must allow the user to set the input parameters and to visualize the results of the simulation through an easy to use interface. The choice is therefore focused on the use of Excel to achieve an interface, which has the advantage of being known and mastered by all.

Rough line boring FEM tool - Calculation Methodology. The cutting force for each tooth of the reamer is applied to the circles which their radius is about twice of bore liner thickness. The aim is to spread the load across multiple nodes instead of applying one-time effort on each node that has no physical meaning. Application of the efforts of a reamer to 3 teeth). It is possible to simulate the tool trajectory by a simple static model and an elastic-plastic constitutive law. Indeed, the ABAQUS software allows the linking calculations via steps through a Python sub-routine. Thus, we can model the efforts of the tool at time $(\mathrm{t}+1)$ by applying a new step of calculation, on the circles which have an angular offset, compared to the tool position at time: Position of the tool at time $t+1$ ). According to this methodology, we can model the cutting forces created by the reamer for each level of bore liner. Successive positions of cutting forces over the bore liners).

All the steps defined in the simulation allow us to apply cutting efforts on 3 levels of bore liner: top, middle and bottom, corresponding to 3 levels of metrology control. The number of calculations or steps depends on the number of cylinder block's bores and the number of required tool position to perform the machining. From one side the number of the reamer teeth and from the other side the diameter of the bore liner for each level (top, middle, and bottom) is needed, to identify the numbers of successive circles/ nodes for applying cutting forces.

$$
n b_{\text {calculations }}=n b_{\text {levels }} \times n b_{\text {bores }} \times \frac{n b_{\text {circles } / \text { levels }}}{n b_{\text {toot } h}}
$$

The output of the FE calculation will be an Excel file with two types of results:

- First results contain the displacements of each bore as a function

- of the tool path and level of the bore liner in the moment of the line boring process;

- Second results contain the displacements of each bore as a function of bore liner level after line boring process.

The tool will run through a python script that 
- Creates data layout for ABAQUS by generating .inp file in with the boundary conditions such as iso-statisme condition, clamping pressures, material properties and the corresponding cutting forces for line boring process are defined;

- Starts ABAQUS software and runs .inp file on Renault's calculation server;

- Carries out the results post-processing in .dat file generated by ABAQUS software and presents them in an Excel file.

The tool can then be divided into three sub-routines (see Fig.2 and Fig.3):

- Sub-routine corresponding to the entries that are defined in the Excel interface;

- Sub-routine for the data layout and calculation defined by Python routines and ABAQUS solver;

- Sub-routine corresponding to the outputs presented in an Excel file.

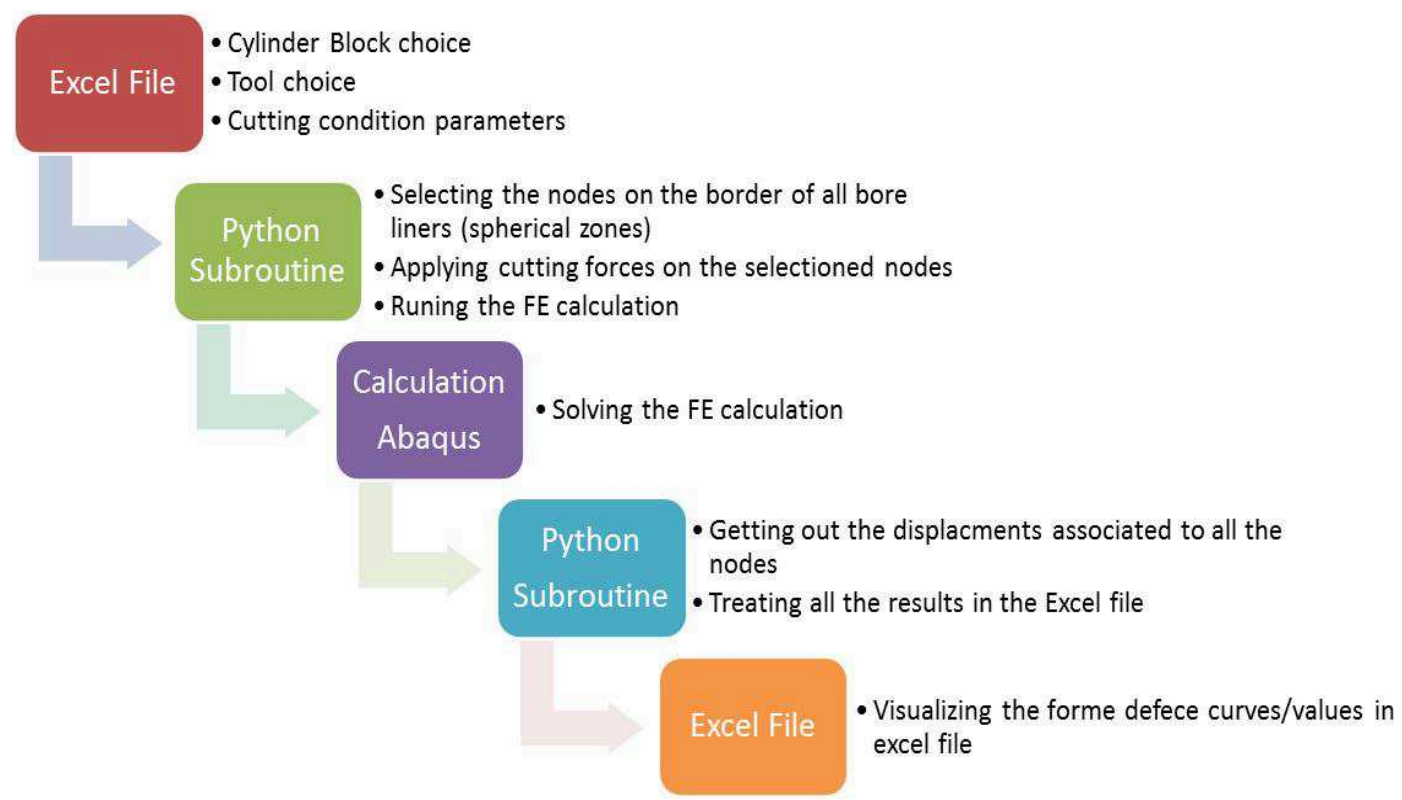

(Fig.2: Rough line boring FEM tool- Calculation Methodology)

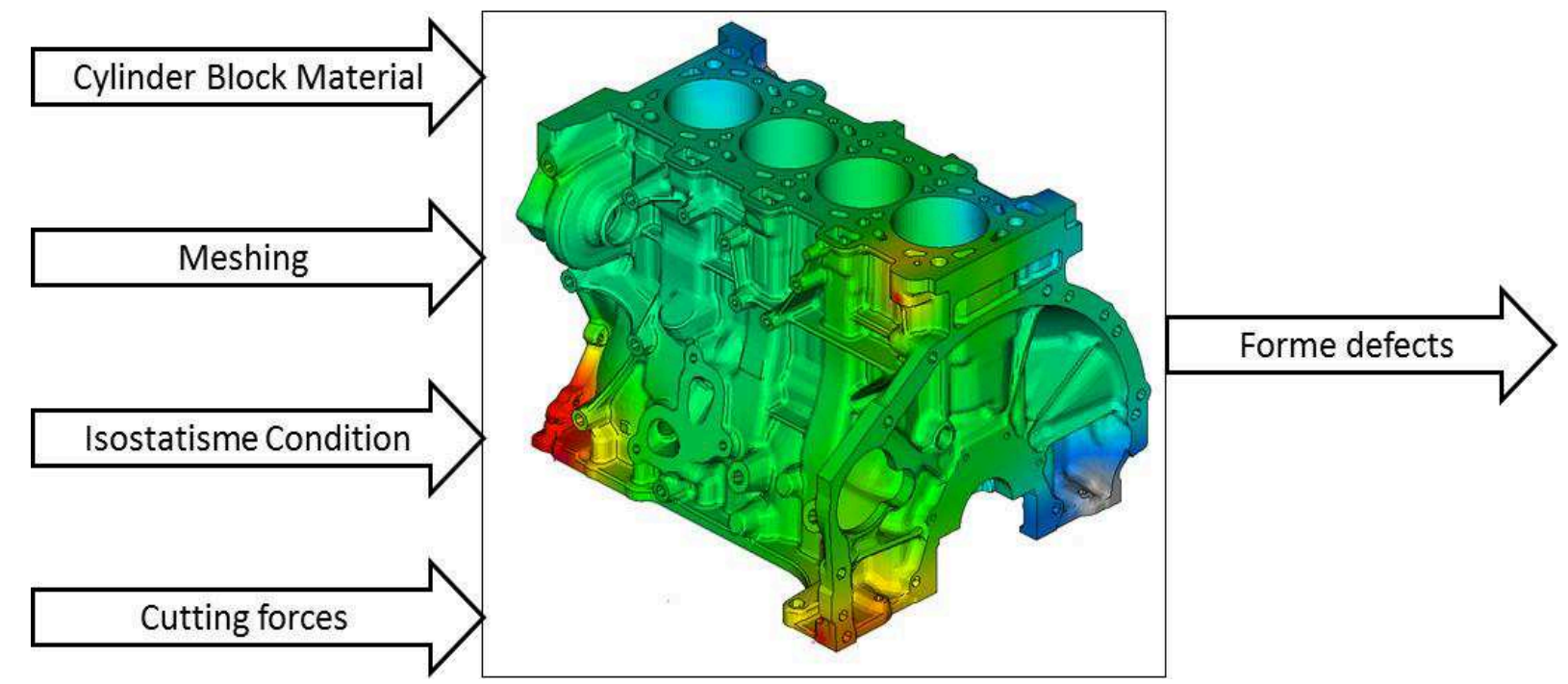

(Fig.3: Rough line boring FEM tool- Calculation Methodology) 


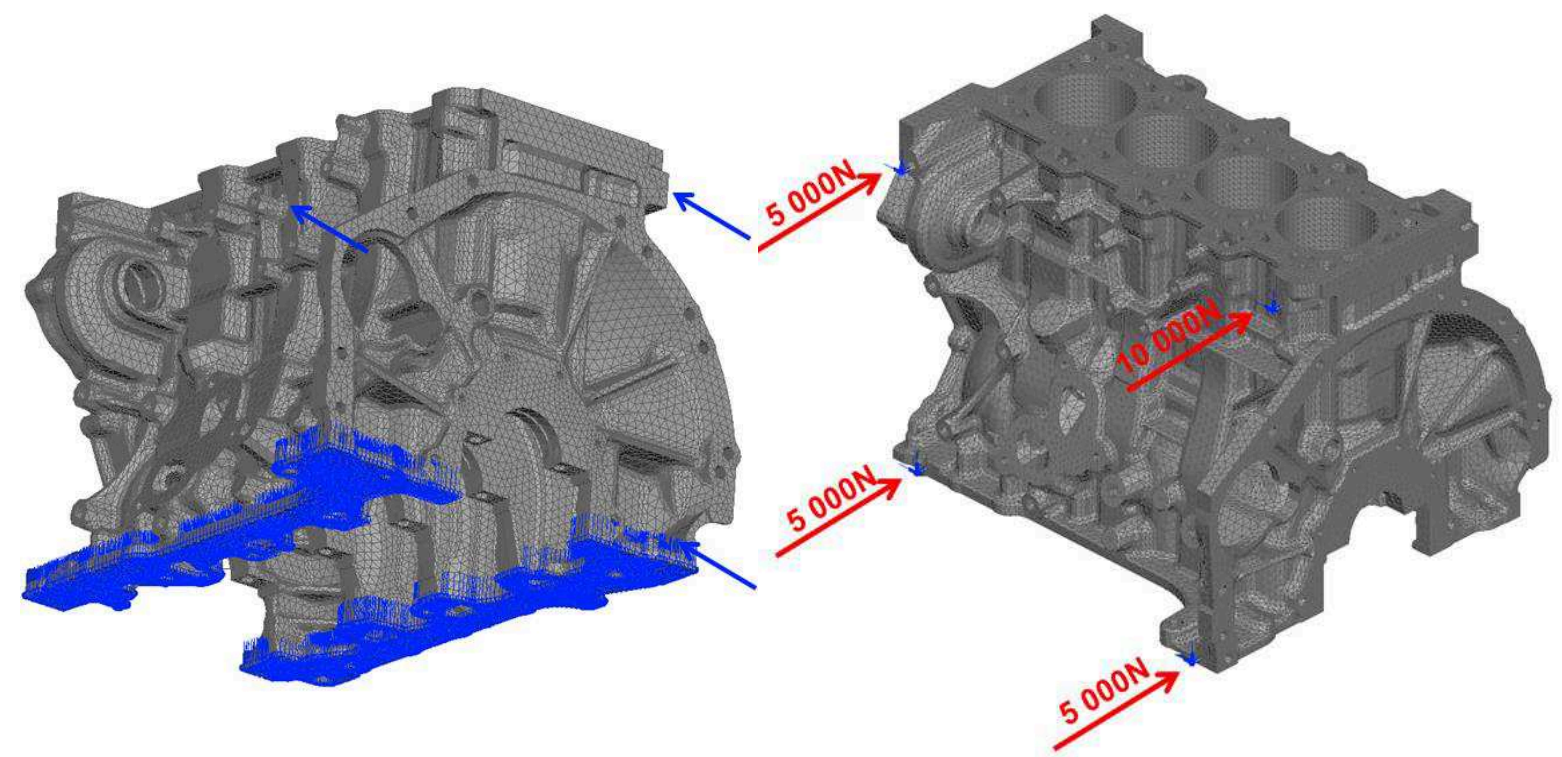

(Fig.4: Boundary conditions during the process- constraint surface- lock pads-clamping forcess)
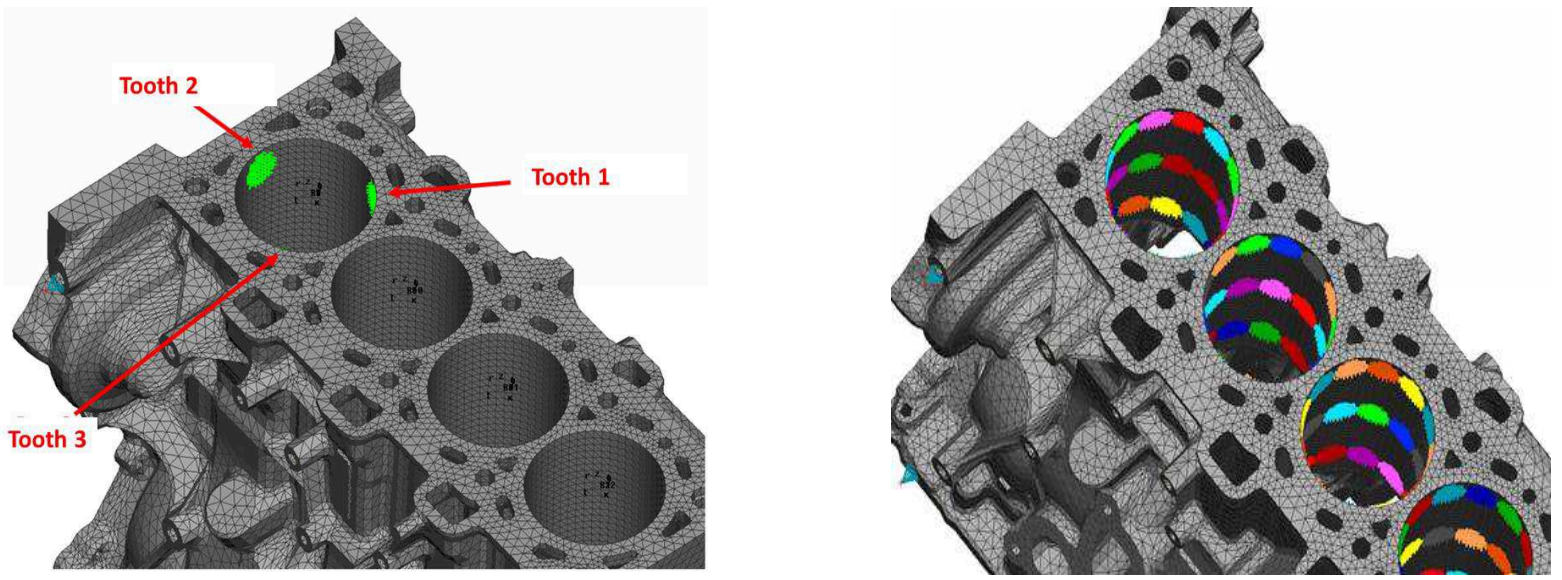

(Fig.5: Rough line boring FEM tool- Calculation Methodology)

\section{Industrial Application of the FE tool}

The methodology is tested for a prototype cylinder block in an automotive company. Fuel efficiency requirements whether based on fuel consumption, fuel economy, or $\mathrm{CO}_{2}$ have made and will continue to make a profound impact on the automotive industry.

The aim of the simulation was to confirm the cutting process parameters (iso-statisme, cutting condition...) from one side and to predict the bore liner form defect (circularity, cylindricity, displacements...), after the process, from another side. A comparative numerical study is performed between the cylinder block manufactured in the production line (type A) and the prototype one with mass reduction (Type B).

Same cutting forces were applied over 3 levels of the bore for each cylinder block. The final results did not show a big difference in terms of the displacements observed between 2 cylinder blocks. These calculations helped us to avoid several prototypes manufacturing and tests in order to validate the Product-Process parameters.

Kienzle law for industrial application. The same cutting condition is applied on both cylinder blocks: the one in the manufacturing lines (Type A) and the prototype one with $2 \mathrm{~kg}$ of mass reduction (M9TGEN4 light). The cutting conditions are as follow: 
Via these cutting conditions and the values found in literature for Kienzle coefficients: $\mathrm{K}_{\mathrm{i}, 1,1}$ and $\mathrm{m}_{\mathrm{i}}$, the cutting forces are calculated. These coefficients are related directly to the interaction between the cutting tool and the cylinder block (cast-iron) materials. A simple elasto-plastic constitutive law is used in ABAQUS software to compute the mechanical properties of both cylinder blocks.

$$
\begin{array}{lll}
K_{c}=950 & m_{c}=0.28 & \mathrm{~h}=0.25 \mathrm{~mm} \\
F_{c}=822.8 N & F_{f}=493.7 N & F_{p}=246.9 N
\end{array}
$$

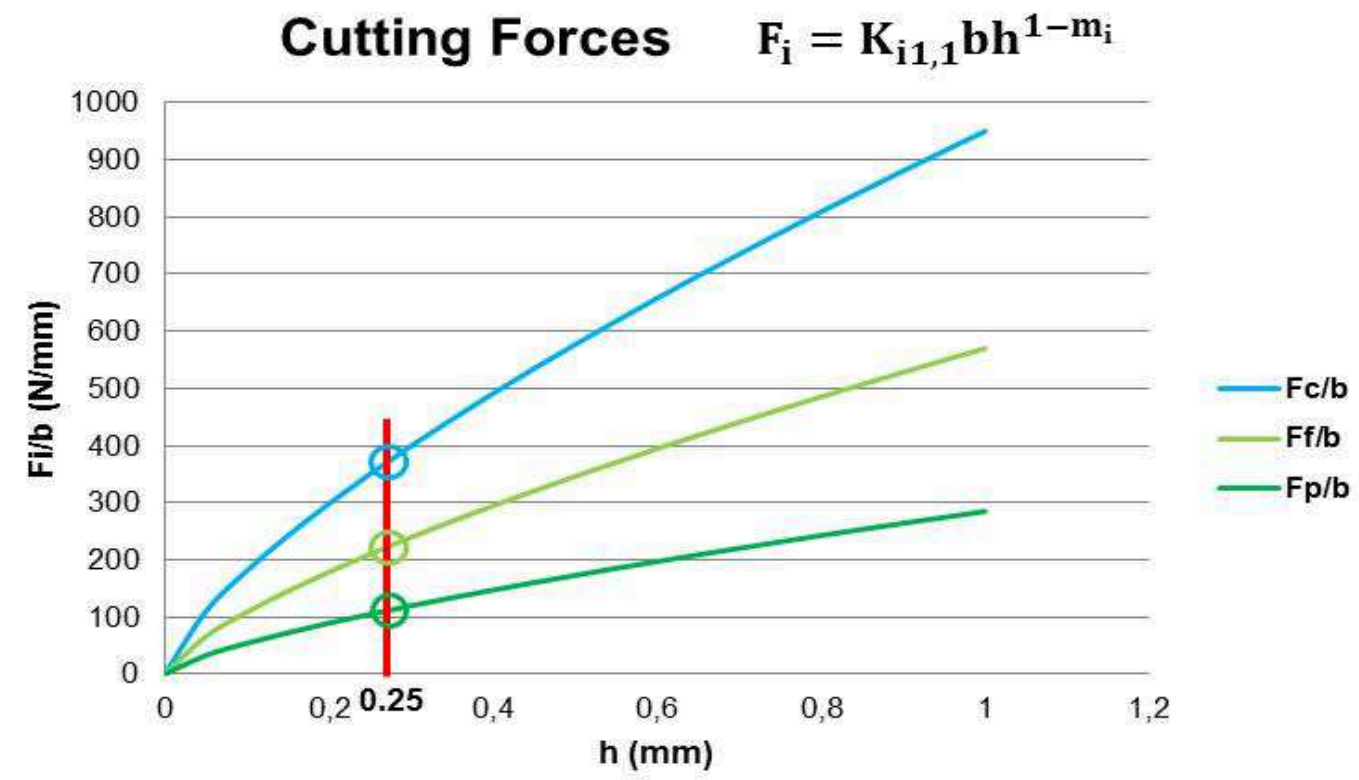

(Fig.6: Cutting forces by Kienzle law)

It seems that the cutting forces obtained by Kienzle law are very low values. The cutting force values should be optimized by accurate measurement of Kienzle coefficients: $K_{i, 1,1}$ and $m_{i}$ through experimental tests (See Fig.6).

Main results of modeling for industrial application. Different scenarios are studied for cylinder block type A and B:

1. Bore distortion under clamping pressures for type A;

2. Bore distortion under cutting forces without any clamping pressure for type A;

3. Bore distortion under both clamping condition and cutting forces for both types A and B.

Four clamping forces ( 3 forces equal to $5 \mathrm{KN}$ and one force equal to $10 \mathrm{KN}$ ) are applied to one face of cylinder block and for each clamping point in the opposite face there is a constrained point to assure the stability of the part during machining process. The results for the first scenario are shown in Fig.7. It seems that the bores are more displaced and less distorted. Bore number 4, is slightly distorted in addition to the displacement. This can be explained by the fact the clamping forces are stronger close to the bore number 4 in compare with the others. 


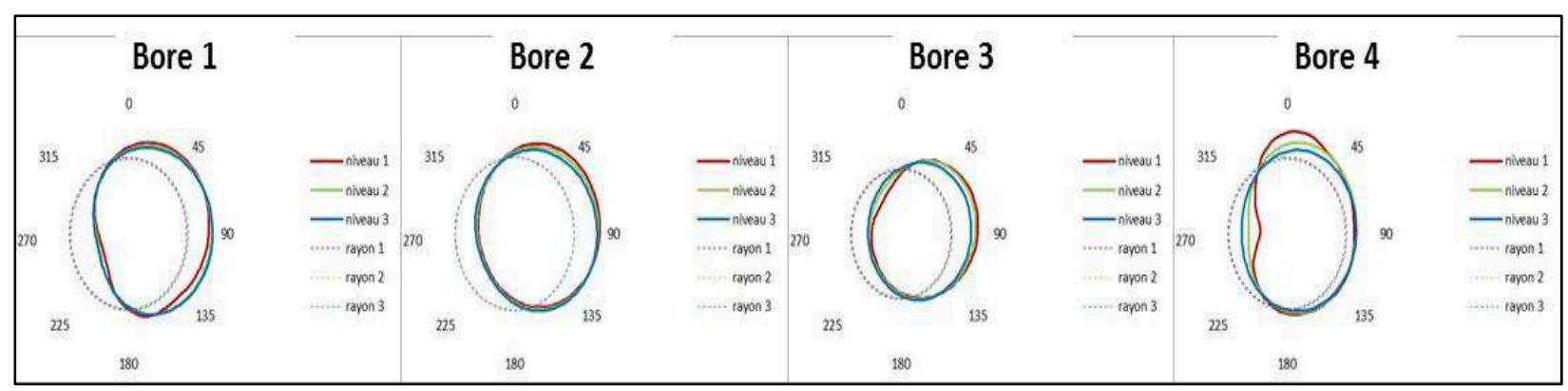

(Fig.7: Bore distortion for type A cylinder block under clamping forces)

Results for the second scenario are illustrated in Fig.8. The distortion of the bores is studied for one tool position (for a reamer with 3 teeth). The distortion due to the cutting process is not very important compared to the displacement obtained under clamping forces (see Fig.7 and Fig.8)

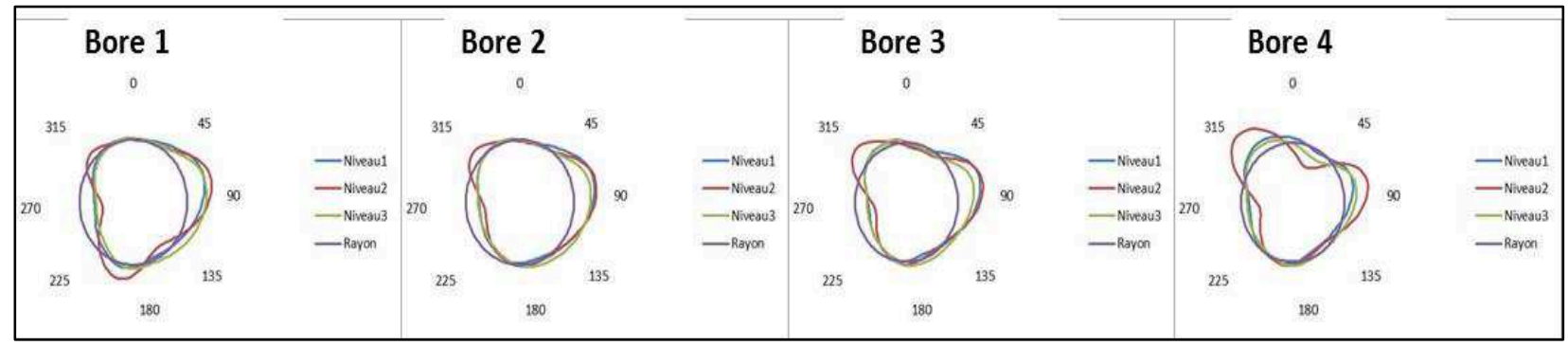

(Fig.8: Bore distortion for type A cylinder block under cutting forces)

Finally when the clamping condition and the cutting forces are mixed together and the results are as follows (see Fig.9):

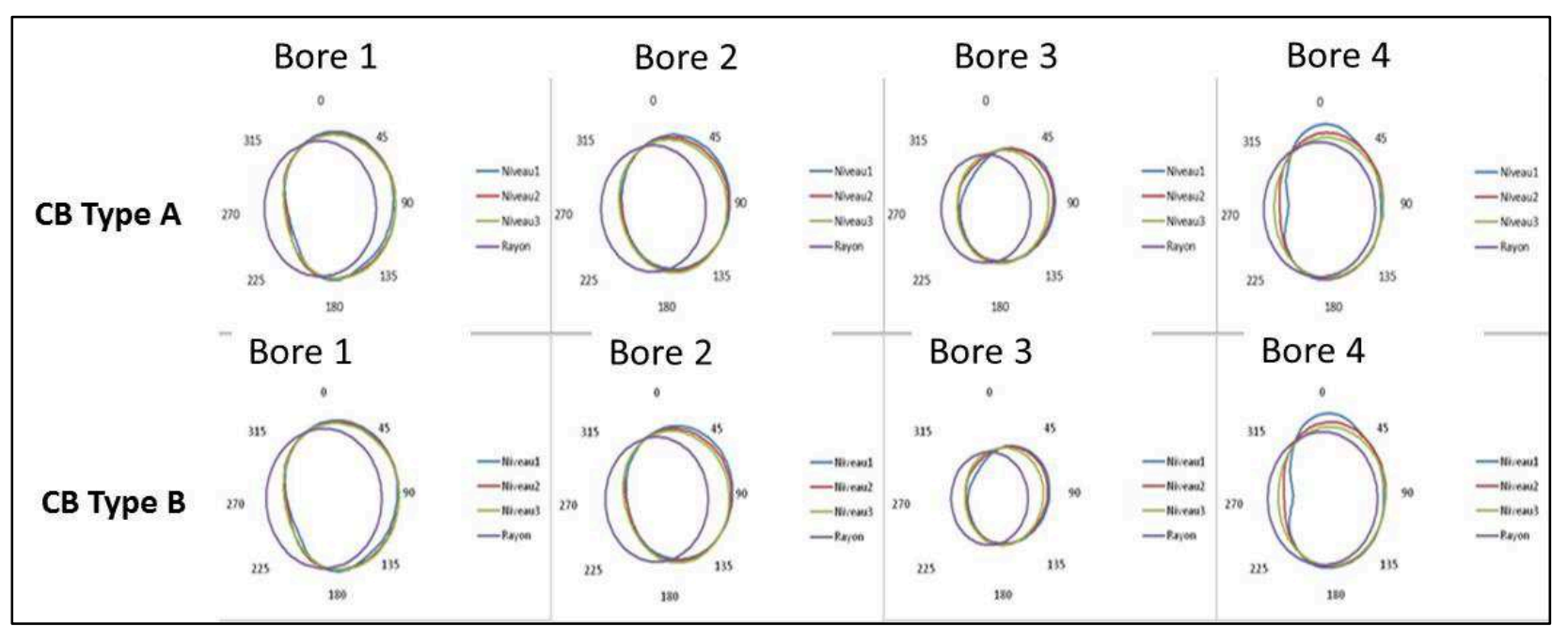

(Fig.9: Bore distortion comparison between type A and B cylinder blocks under cutting and clamping forces)

Comparison of displacements and distortions between M9TGEN4 and M9TGEN4 light shows that the difference of rigidity between the cylinder blocks, is not significant (less than $8 \%$ ). Thus, the mass reduction of $2 \mathrm{Kg}$ did not have an important impact on the cylinder block's rigidity. These calculations confirmed the cutting parameters of the prototype cylinder block (M9TGEN4 light). 
Simulation and experimental correlation. The experimental tests are conducted on the prototype cylinder blocks. The idea of these experiments was to measure the circularity default of cylinder bores on the top, middle and the bottom of the bore, before and after rough bore lining process, over 2 prototype cylinder blocks. Unfortunately due to the confidentiality issue, these results are not demonstrated in this paper. The first metrologies on the rough part, before and after the process, showed that the first influent factor which disturbs the correlation between the simulation and experimentation is the initial form defect of rough part due to the casting process. Integration of casting form defect in the simulation is crucial and should be taken into account in the next studies.

\section{Summary}

This study presents a simple model of cutting forces via Kienzle law. Once the cutting forces are computed, a Python routine is developed for activating the ABAQUS software and imposing the boundary conditions. Finally the form defect results (circularity, cylindricity, displacements,) are shown in an excel interface. The FE tool is tested for a new prototype cylinder block. The comparative simulations between the cylinder block in the production line and the prototype one proved that the mass reduction will not significantly change the rigidity of the part. The same cutting parameters are chosen for the prototype cylinder block thanks to this modeling. The simulations showed that clamping conditions play an important role in the bore distortion of the cylinder blocks. Impact of clamping forces in some cases (cast-iron cylinder blocks) can be more important than the cutting forces, so it is essential to optimize the clamping conditions in the first stage of process.

\section{References}

[1] Luc MASSET, Jean-François DEBONGNIE, Audrey MARTY - Machining process simulation using SAMCEF superelement- 9th SAMTECH Users Conference 2005

[2] C.A. Van Luttervelt, T.H.C. Childs, I.S. Jawahir, F. Klocke, P.K. Venuvinod, Present situation and future trends in modeling of machining operations, Annals of CIRP 47 (2) (1998) 578-626.

[3] K.F. Ehman, S.G. Kapoor, R.E. Devor, Unknown Lazoglu, Machining process modeling: a review, Journal of Manufacturing Science and Engineering, Trans. of ASME 119 (1997) 655-663.

[4] Gu F., Melkot S. N., Kapoor S. G., Devor R. E., A Model for the Prediction of Surface Flatness in Face Milling, ASME Journal of Manufacturing Science and Engineering vol. 119, pp. 476-484, 1997.

[5] Y. Altintas. Manufacturing automation. Metal Cutting Mechanistics, Machine Tool Vibrations, and CNC Design. Cambridge University Press, 2000, 286 p.

[6] G. Subramani, S. G. Kapoor and R. E. DeVor, A Model for the Prediction of Bore Cylindricity During Machining, J. Manuf. Sci. Eng. 115(1), 15-22 (Feb 01, 1993)

[7] Ismail Lazoglu, Fuat Atabey, Yusuf Altintas- Dynamics of boring processes: Part III-time domain modeling - International Journal of Machine Tools \& Manufacture 42 (2002) 1567-1576

[8] M.Sc. Karla P. Monroy Vazquez, Claudio Giardini and Elisabetta Ceretti, Cutting force modeling, springer Reference, 1 July 2013 1-20

[7] F. Atabey, I. Lazoglu, Y. Altintas- Mechanics of boring processes- Part I- International Journal of Machine Tools \& Manufacture 43 (2003) 463-476 
[8] F. Atabey, I. Lazoglu, Y. Altintas - Mechanics of boring processes-Part II—multi-insert boring heads- International Journal of Machine Tools \& Manufacture 43 (2003) 477-484

[9] Y. Zheng, H. Li, W. W. Olson, J. W. Sutherland- Evaluating Cutting Fluid Effects on Cylinder Boring Surface Errors by Inverse Heat Transfer and Finite Element Methods- Journal of Manufacturing Science and Engineering 122 (2000) 377-383

[10] Black SC, Chiles V, Lissaman AJ, Martin SJ (1996) Principles of engineering manufacture, 3rd edn. Butterworth-Heinemann, Oxford

[11] Sebastien Campocasso, Jean-Philippe Costes, Gerard Poulachon and Alexis Perez-DuarteCutting Forces Modeling in Finish Turning of Inconel 718 Alloy with Round Inserts, 13th CIRP Conference on Modelling of Machining Operations, May 2011, Sintra, Portugal. Modelling of Machining Operations (223), pp.75-84

[12] L. Masset, B. Deltour, Etude de faisabilité numérique de l'usinage - Rapport $n^{\circ} 4$ - Modèle de forces de coupe 